\title{
Acute coronary syndrome in the young Nepalese population with their angiographic characteristics
}

\author{
Shankar Laudari, Sachin Dhungel, Laxman Dubey, Rajesh Panjiyar, Madhu Gupta, Gagnapatnam \\ Subramanyam, Pawina Subedi, Bindesh Ghimire \\ Department of Cardiology, College of Medical Sciences-Teaching Hospital, Bharatpur, Chitwan, Nepal
}

Correspondence
Dr. Shankar Laudari
MD, DM Cardiology
Department of Cardiology
College of Medical Sciences-
Teaching Hospital
Bharatpur-10,Chitwan,Nepal
Email:
lshankar2@hotmail.com
ORCID ID:
http://orcid.org/0000-0002-6742-5631

DOI: http://dx.doi.org/10.3126/ jcmsn.v13i2.17147

Article received: $11^{\text {th }}$ April 2016 Article accepted: $27^{\text {th }}$ June 2017

\begin{abstract}
Background \& Objectives: Acute coronary syndrome (ACS) is an emerging cardiac problem in the young population in Asia and Nepalese population is not an exception to this. Early ACS in young age imparts huge familial and social economic burden. Early identification and proper management strategy is still a challenging problem in developing countries like Nepal where there are limited coronary intervention centers. The study was conducted with objective to study the clinical spectrum, etiologies, coronary angiographic characteristics and their clinical outcomes. Materials \& Methods: This is a cross-sectional study carried out in a tertiary hospital in central Nepal. Forty patients with acute coronary syndrome with age less than 40 years were enrolled in the study. Results: Majority of the patients were males with male: female=1.8:1. Twenty six $(65 \%)$ patients were having ST segment elevation myocardial infarction followed by non-ST elevation myocardial infarction in nine $(22.50 \%)$ patients and unstable angina in five $(12.50 \%)$. patients. The most common risk factors were smoking, systemic hypertension, diabetes mellitus and dyslipidemia. Majority were having single vessel disease. Twenty $(50 \%)$ patients had undergone primary angioplasty followed by thrombolysis in seven patients and the rest were managed medically because of late presentation. In-hospital major adverse cardiac events and mortality were higher among STEMI than NSTEMI and unstable angina. Conclusion: Acute coronary syndrome in the young is increasing in the Nepalese population. This group of population should be well educated and made aware of the potential coronary risk factors and their modification.
\end{abstract}

Key words: Acute coronary syndrome; angiography; angioplasty; outcome

Citation: Laudari S, Dhungel S, Dubey L, Panjiyar R, Gupta M, Subramanyam G, Subedi P, Ghimire B. Acute coronary syndrome in the young Nepalese population with their angiographic characteristics. JCMS Nepal. 2017;13(2):235-40.

\section{INTRODUCTION}

Acute coronary syndrome is a common presentation of ischemic heart disease. It is the single largest cause of death in developed countries as well as developing countries. ${ }^{1}$ On currently available evidence, young patients represent $0.4 \%$ to $19 \%$ of all acute coronary syndrome (ACS) cases, depending on the cut-off age used..$^{2-4}$ As classic coronary atherosclerotic plaque rupture is considered to be rare during the early decades of life, uncommon etiologies may be considered. The cardiovascular risk factors, the extent of coronary artery disease and clinical outcome after ACS might be different from those of older patients. ${ }^{5-8}$

Acute coronary syndrome is not uncommon in the young population as previously thought. Undersuspicion of the diagnosis and mostly attributing chest pain or epigastric pain to either acid peptic disorder or alternative musculoskeletal causes leads to misdiagnosis and mismanagement of the 
patients. These patients are referred to our tertiary center usually very late. Also, being Nepal a mountainous country and poor condition of the roads and transport system, these patients usually present after the golden hours of the myocardial salvage time. It's a high time that the government and the health policy makers should understand this fact and co-operate with other related health sectors to salvage these young patients timely. More dedicated and well equipped cardiac centers should be available for better outcome.

There are very limited studies from central Nepal to share experience of presentation, etiology, diagnosis, management and outcome of ACS patients. So, we believe this study will be very useful to lay the foundation for further large studies and extrapolate more information in Nepal.

This study was designed to study the different patterns of acute coronary syndrome in the young population. Also, it was intended to describe the probable coronary risk factors, study the etiology/ angiographic characteristics of the ACS spectrum and their clinical outcome.

\section{MATERIALS AND METHODS}

This is an observational cross-sectional study conducted at College of Medical Sciences-Teaching Hospital, Bharatpur, Nepal. The study population for the present analysis was selected from the inpatients with acute coronary syndrome who underwent coronary angiography between August 2014 and August 2016. Inclusion criteria involved:

(i) patients admitted for STEMI, NSTEMI or UA

(ii) more than 18 years and $<40$ years of age and (iii) those who underwent coronary angiography.

The term acute coronary syndrome (ACS) refers to any group of clinical symptoms compatible with acute myocardial ischemia and includes unstable angina (UA), non-ST-segment elevation myocardial infarction (NSTEMI), and ST-segment elevation myocardial infarction (STEMI).

Medical records were reviewed which included proper medical history, drug abuse, smoking, physical examination, homocysteinaemia, antiphospholipid antibody titre, other thrombophilic conditions, lipid profiles, coronary angiography, 12 -lead electrocardiogram (ECG), percutaneous coronary intervention (PCI) as well as postprocedural echocardiography.

Dyslipidemia was defined in accordance with the reports of the National Cholesterol Education Programme (Adult Treatment Panels II and III). ${ }^{9}$ Hyperhomocysteinaemia was considered present when plasma concentrations were $>15 \mu \mathrm{mol} / \mathrm{l}$.

MACE was defined as the occurrence of cardiac death (CD), nonfatal myocardial infarction (MI), or target vessel revascularisation (TVR) during the follow-up period.

The target lesion was defined as the treated segment from $5 \mathrm{~mm}$ proximal to the stent to $5 \mathrm{~mm}$ distal to the stent.TVR was defined as any repeat PCI of any segment of the target vessel, defined as the entire major coronary vessel proximal and distal to the target lesion, including upstream and downstream branches and the target lesion itself. Any death due to approximate cardiac cause, all unwitnessed deaths and deaths of unknown causes were considered cardiac. Definite, probable and possible stent thromboses were determined in accordance with the Academic Research Consortium (ARC) definitions. ${ }^{10}$ Stent thrombosis was defined as early, late or very late if the event occurred within 30 days, $<1$ year or $>1$ year, respectively, after the procedure.

\section{Ethical consideration}

The study was approved by the Institute's ethical committee. Written and verbal informed consents were obtained from all participants.

Data collection was made from the hospital records of the selected patients. Coronary risk factors like smoking, hypertension, diabetes, dyslipidemia, obesity and family history of CAD were assessed. Few of the patients were also evaluated for coagulation abnormalities and vasculitis disorders. Body-mass index (BMI) was estimated based on the height and weight measurements to identify obese patients (BMI $>25 \mathrm{~kg} / \mathrm{m} 2$ ). Patients were categorized as smokers if they reported smoking/ tobacco/tobacco products consumption within last one year of study enrollment.

Coronary angiography was done using 6Fr Judkin's diagnostic catheters or $5 \mathrm{Fr}$ Tiger catheter via the femoral artery and radial artery approach. Coronary artery disease (CAD) 11 was defined as the presence of a $>70 \%$ lesion in one of the three major coronary arteries [i.e. left anterior descending coronary artery (LAD), left circumflex coronary artery (LCX), and right coronary artery (RCA)] or their major branches, or $>50 \%$ luminal narrowing of the left main coronary artery (LMCA). Accordingly, patients were classified as having single-vessel, double-vessel or triple- vessel disease.

\section{Statistical analysis}

Continuous measurements are presented as mean \pm standard deviation, while categorical measurements are presented as frequency (percentage). Two-tailed 
Student's t-test was used to find the significant differences between two groups for study parameters on continuous scale. Chi-square/ Fisher's exact test was used to find the significant differences between two groups for study parameters on categorical scale. Statistical difference was assessed at 95\% level of significance. The Statistical Package for Social Sciences (SPSS 16) was used to analyze the data.

\section{RESULTS}

Total 360 patients with acute coronary syndrome were admitted in our tertiary hospital CCU during a period of 36 months from August 2014 to August 2016 out of whom 40 patients (11.11\%) belonged to the young ( $<40$ years). Males were predominant in this study with male(26) to female(14) ratio 1.8:1. The following Table 1 illustrates the baseline characteristics of the patients.

\section{Table 1: Comparison of baseline clinical characteristics of ACS patients along with coronary risk factors (n-40)}

\begin{tabular}{|c|c|c|c|c|}
\hline \multirow[t]{2}{*}{ Variables } & \multirow[t]{2}{*}{ ASTEMI(n-26) } & \multicolumn{2}{|c|}{ NSTEMI and UA } & \multirow[t]{2}{*}{$P$ value } \\
\hline & & NSTEMI(n-9) & $\mathrm{UA}(\mathrm{n}-5)$ & \\
\hline Age in years, Mean \pm SD & $35 \pm 4.2$ years & $32 \pm 6.1$ years & $33 \pm 5.6$ years & 0.42 \\
\hline $\begin{array}{l}\text { Sex } \\
\text {-Male, } \mathrm{n}(\%) \\
\text {-Female, } \mathrm{n}(\%)\end{array}$ & $\begin{array}{l}16(40 \%) \\
9(22.5 \%)\end{array}$ & $\begin{array}{l}7(17.5 \%) \\
3(7.5 \%)\end{array}$ & $\begin{array}{l}3(7.5 \%) \\
2(5.0 \%)\end{array}$ & $\begin{array}{l}0.07 \\
0.06\end{array}$ \\
\hline Other coronary risk factors & & & & \\
\hline Smoking & 20 & 6 & 4 & 0.51 \\
\hline $\begin{array}{l}\text { Tobacco chewing/tobacco } \\
\text { related products }\end{array}$ & 4 & 2 & 0 & 0.60 \\
\hline Systemic hypertension & 16 & 4 & 3 & 0.42 \\
\hline Diabetes mellitus & 4 & 3 & 2 & 0.31 \\
\hline Dyslipidemia & 7 & 2 & 1 & 0.20 \\
\hline -Elevated LDL & 3 & 1 & 1 & \\
\hline -Low HDL & 3 & 0 & 0 & \\
\hline -Elevated TG & 1 & 1 & 0 & \\
\hline Family history & 4 & 1 & 0 & 0.34 \\
\hline Obesity & 8 & 2 & 0 & 0.42 \\
\hline Coagulation abnormalities & 3 & 0 & 0 & 0.04 \\
\hline -Thrombophilia & 1 & 0 & 0 & \\
\hline -Protein $\mathrm{C}$ and $\mathrm{S}$ deficiency & 2 & 0 & 0 & \\
\hline Vasculitis & 2 & 0 & 0 & 0.43 \\
\hline Clinical presentation & & & & \\
\hline -Chest pain & 22 & 8 & 4 & 0.50 \\
\hline -Shortness of breath & 2 & 1 & 1 & 0.61 \\
\hline -Syncope & 1 & 0 & 0 & 0.34 \\
\hline -Atypical symptoms & 1 & 0 & 0 & 0.41 \\
\hline Complications & & & & 0.51 \\
\hline -Cardiogenic shock & 5 & 0 & 0 & \\
\hline$-\mathrm{VT} / \mathrm{VF}$ & 3 & 1 & 0 & \\
\hline -Sudden cardiac arrest & 1 & 0 & 0 & \\
\hline $\begin{array}{l}\text {-Mechanical(IV septal } \\
\text { rupture) }\end{array}$ & 0 & 0 & 0 & \\
\hline
\end{tabular}

Note: ASTEMI-acute ST elevation myocardial infarction, NSTEMI-Non-ST elevation myocardial infarction, UA-unstable angina, SD-standard deviation, LDL-Low density lipoprotein, HDL-High density lipoprotein, TG-Triglyceride, VT/VF- ventricular tachycardial ventricular fibrillation, IV-interventricular septal rupture 
Table 2: Coronary angiography characteristics and modalities of treatment (n-40)

\begin{tabular}{|c|c|c|c|c|}
\hline \multirow[t]{2}{*}{ Variables } & \multirow[t]{2}{*}{ ASTEMI(n-26) } & \multicolumn{2}{|c|}{ NSTEMI and UA } & \multirow[t]{2}{*}{$\mathrm{P}$ value } \\
\hline & & NSTEMI $(n=9)$ & $\mathrm{UA}(\mathrm{n}=5)$ & \\
\hline \multicolumn{5}{|l|}{$\begin{array}{l}\text { No. of coronaries } \\
\text { involved/lesion } \\
\text { severity }\end{array}$} \\
\hline -Non-critical CAD & 0 & 0 & 1 & NA \\
\hline -SVD & 18 & 5 & 3 & 0.04 \\
\hline -DVD & 6 & 3 & 2 & 0.35 \\
\hline -TVD & 2 & 1 & 0 & 0.60 \\
\hline \multicolumn{5}{|l|}{$\begin{array}{l}\text { Location of } \\
\text { coronary lesion }\end{array}$} \\
\hline -Left main & 3 & 0 & 0 & 0.36 \\
\hline$-\mathrm{LAD}$ & 9 & 5 & 2 & 0.09 \\
\hline$-\mathrm{LCX}$ & 4 & 1 & 1 & 0.67 \\
\hline$-\mathrm{RCA}$ & 10 & 3 & 2 & 0.45 \\
\hline \multicolumn{5}{|l|}{$\begin{array}{l}\text { Treatment } \\
\text { modalities }\end{array}$} \\
\hline $\begin{array}{l}\text {-Thrombolysis } \\
\text { With streptokinase }\end{array}$ & 6 & 0 & 0 & 0.03 \\
\hline $\begin{array}{l}\text {-Thrombolysis with } \\
\text { Tenecteplase }\end{array}$ & 1 & 0 & 0 & NA \\
\hline $\begin{array}{l}\text {-Optimal medical } \\
\text { therapy }\end{array}$ & 4 & 4 & 3 & 0.36 \\
\hline -Primary PCI & 14 & 5 & 1 & 0.04 \\
\hline -POBA & 1 & 0 & 0 & NA \\
\hline -CABG & 0 & 0 & 1 & NA \\
\hline
\end{tabular}

Note: CAD-coronary artery disease, SVD-single vessel disease, DVD-double vessel disease, TVD-triple vessel disease, LAD-left anterior descending, LCX-left circumflex, RCA-right coronary artery, PCIpercutaneous coronary intervention, POBA-Plain old balloon angioplasty, CABG-coronary artery bypass graft, NA-Not applicable

All the patients enrolled in the study had undergone coronary angiography. Their angiographic characteristics and the modalities of treatment including angioplasty has been illustrated in Table 2. Critical CAD with SV involvement was most common among STEMI patients. Three of the patients had left main lesion.

The patients were managed with thrombolysis/ fibrinolysis, PTCA (percutaneous angioplasty) and few patients had undergone CABG. In hospital outcomes of the patients was the best among those with unstable angina rather than STEMI and NSTEMI as shown in Table 3. In hospital mortality was $2(5 \%)$ which was contributed by ASTEMI.

\section{DISCUSSION}

In our study, there were 40 young patients $(11.11 \%)$ with ACS out of total 360 patients. Earlier, studies have reported that only about $3 \%$ of all CAD cases occur in $<40$ years of age, which should be measured as the 'tip of the iceberg' since young asymptomatic patients usually do not undergo medical investigations. ${ }^{12}$

Smoking/tobacco consumption was identified as the most prevalent risk factor in patients in the STEMI group as well as in the NSTEMI/UA group in our study. The literature reports smoking by up to $82 \%$ of young patients suffering from ACS. ${ }^{13}$ Case control studies indicate that smoking is an independent risk factor for the development of ischemic heart disease in young patients. ${ }^{14}$ Smoking persistence is associated with the occurrence of secondary events after MI in young patients. Taken together, these data underline the importance of primary and secondary prevention specifically in this subset of patients. Ralldis and colleagues showed that decreased left ventricular ejection fraction at presentation and the continuation of smoking after myocardial infarction were most predictive for further MACEs in young patients. ${ }^{15}$ 
Table 3: In-hospital outcome of the patients (n-40)

\begin{tabular}{|c|c|c|c|c|}
\hline Variables & ASTEMI & NSTEMI & UA & $\mathrm{P}$ value \\
\hline In-hospital MACE, n(\%) & $3(7.5 \%)$ & $1(2.5 \%)$ & $0(0 \%)$ & 0.46 \\
\hline In-hospital mortality, n(\%) & $2(5 \%)$ & $0(0 \%)$ & $0(0 \%)$ & 0.70 \\
\hline $\begin{array}{l}\text { In-hospital periprocedural } \\
\text { MI, } \mathrm{n}(\%)\end{array}$ & $0(0 \%)$ & $0(0 \%)$ & $0(0 \%)$ & NA \\
\hline $\begin{array}{l}\text { In-hospital stent thrombosis, } \\
\mathrm{n}(\%)\end{array}$ & $0(0 \%)$ & $0(0 \%)$ & $0(0 \%)$ & NA \\
\hline Recovery(uncomplicated) & $21(52.50 \%)$ & $8(20 \%)$ & $5(12.50 \%)$ & 0.04 \\
\hline
\end{tabular}

Note: MACE-Major adverse cardiac events, NA-Not applicable

Since it is a preventable risk factor, we recommend that healthy life styles should be encouraged and new precautions about smoking/tobacco consumption must be undertaken to combat high incidence of CAD.

Apart from the classical risk factors for CAD, young patients are likely to have other risk factors like coagulation abnormalities (Thrombophilia, Protein $\mathrm{C}$ and $\mathrm{S}$ deficiency) and vasculitis which contributed to five $(12.50 \%)$ in our study. Serban et $\mathrm{al}^{16}$ reported unusual condition in ten patients [37\%, nonatherosclerosis (non-ATS) group]: hereditary thrombophilia with or without patent foramen ovale in four patients (15\%), cocaine abuse in two (7\%), Kawasaki and familial Mediterranean fever in two $(7 \%)$, emboli in infective endocarditis in one (4\%), and antiphospholipid antibody syndrome in one $(4 \%)$.

In coronary angiography, single vessel disease was more common than DVD and MVD.SVD was more associated with STEMI patients than NSTEMI and UA. Also, LAD was the most common culprit vessel followed by RCA and LCX. Colkesen et al. ${ }^{17}$ involving young STEMI patients with $\leq 35$ year age revealed that $\mathrm{LAD}$ was the most common vessel involved followed by RCA, LCX, and LMCA which was similar to our finding.

Fifty percent of the patients in our series had undergone Primary PCI and the rest managed with medical therapy and $\mathrm{CABG}$.

In hospital MACE was in $4(10 \%)$ patients and 2 patients $(5.0 \%)$ expired during the course of treatment in the hospital. In a study by Serbin et al ${ }^{16}$ in 2013, in-hospital MACE occurred in two patients (7\%): One patient died and another had nonfatal MI as a result of early definite stent thrombosis. This study showed that the procedural outcome was better in the young patients than the elderly group.

In our study, majority of the patients post- revascularisation were doing fine with very less MACE. This satisfactory long-term outcome has already been suggested previously. Possible explanations are the lesser extent of CAD in comparison with older patients, more preserved left ventricular function, and a higher ability of young patients to modify their lifestyle. In line with this, Ralldis and colleagues showed that decreased left ventricular ejection fraction at presentation and the continuation of smoking after myocardial infarction were most predictive for further MACEs in young patients. ${ }^{15}$

\section{CONCLUSION}

The The prevalence of acute coronary syndrome is increasing in the young population and in fact, it attributes to significant mortalities and morbidities in Asia. Single-vessel disease has been found to be predominantly involved in STEMI group, whereas triple-vessel disease was predominant in NSTEMI/ UA group. LAD was the most commonly involved coronary artery in both the groups. Smoking is the most important reversible risk factor in these young groups. Even non-atherosclerotic causes likes coagulation disorders, vasculitis and drus abuse have to be evaluated in these patients. ACS if not diagnosed timely and treated properly in the young population may have serious life-threatening complications and poor outcome. Moreover the complexities of the lesions especially location over the left main and high thrombogenecity of the lesions will further add the challenges in the treatment and outcome.

\section{Conflict of interest}

The authors do not have any conflict of interest in publication of this article. 


\section{REFERENCES}

1. Gaziano TA, Bitton A, Anand S. Growing epidemic of coronary heart disease in low- and middle-income countries. Curr Probl Cardiol. 2010;35:72-115. https:// doi.org/10.1016/j.cpcardiol.2009.10.002. PMID: 20109979.

2. Chen YL, Bhasin A, Youssef AA, Wu CJ, Yang CH, Hsieh $\mathrm{YK}$, et al. Prognostic factors and outcomes in young chinese patients with acute myocardial infarction undergoing primary coronary angioplasty. International Heart Journal. 2009;50:1-11. https://doi.org/10.1536/ ihj.50.1. PMID:19246842.

3. Chan MY, Woo KS, Wong HB, Chia BL, Sutandar A, Tan HC. Antecedent risk factors and their control in young patients with a first myocardial infarction. Singapore Med J. 2006;47:27-30. PMID: 16397717.

4. Morillas P, Bertomeu V, Pabon P, Ancillo P, Bermejo J, Fernandez C, et al. Characteristics and outcome of acute myocardial infarction in young patients. The PRIAMHO II study. Cardiology. 2007;107:217-25. https:// doi.org/10.1159/000095421. PMID: 16953107.

5. Ghosh K, Khare A, Shetty S. Fasting plasma homocysteine levels are increased in young patients with acute myocardial infarction from Western India. Indian Heart $\mathbf{J}$. 2007;59:242-5. PMID: 19124933.

6. Ogawa M, Abe S, Saigo M, Biro S, Toda H, Matsuoka T, et al. Homocysteine and hemostatic disorder as a risk factor for myocardial infarction at a young age. Thromb Res. 2003;109:253-8. https://doi.org/10.1016/S0049-3848(03) 00242-1.

7. Nikfardjam M, Graf S, Hornykewycz S, Zorn G, HuberBeckmann R, Wojta J, et al. Homocysteine plasma levels in young patients with coronary artery disease. Relation to history of acute myocardial infarction and anatomical extent of disease. Thromb Res. 2001;103:35-9. https:// doi.org/10.1016/S0049-3848(01)00295-X.

8. Patrizi R, Pasceri V, Sciahbasi A, Summaria F, Rosano GM, Lioy E. Evidence of cocaine related coronary atherosclerosis in young patients with myocardial infarction. J Am Coll Cardiol. 2006;47:2120-2. https:// doi.org/10.1016/j.jacc.2005.12.060. PMID: 16697335 .

9. Third Report of the National Cholesterol Education Program (NCEP) Expert Panel on Detection, Evaluation, and Treatment of High Blood Cholesterol in Adults (Adult Treatment Panel III) final report. Circulation. 2002;106:3143-421. PMID: 12485966.

10. Cutlip DE, Windecker S, Mehran R, Boam A, Cohen DJ, van Es GA, et al. Clinical end points in coronary stent trials: a case for standardized definitions. Circulation. 2007;115:2344-51. https://doi.org/10.1161/ CIRCULATIONAHA.106.685313. PMID: 17470709.

11. Nikus KC. Coronary angiography; Current methods and their applications for cardiovascular multimodal imaging. In: Pahlm O, Wagner GS. Multimodal cardiovascular imaging: Principles and clinical applications.1st ed. Philadelphia: The McGraw-Hill Companies:2011:57-80.

12. Rumboldt Z, Rumboldt M, Pesenti S, Polic S, Miric D. Peculiarities of myocardial infarction at young age in Southern Croatia. Cardiologia. 1995;40:407-11. PMID: 8640853.

13. Teixeira M, Sa I, Mendes JS, Martins L. Acute coronary syndrome in young adults. Rev Port Cardiol. 2010;29:94755. PMID: 20964107.

14. Hbejan K. Smoking effect on ischemic heart disease in young patients. Heart Views. 2011;12:1-6. https:// doi.org/10.4103/1995-705X.81547. PMID: 21731801

15. 15. Rallidis LS, Lekakis J, Panagiotakos D, Fountoulaki $\mathrm{K}$, Komporozos C, Apostolou $\mathrm{T}$, et al. Long-term prognostic factors of young patients ( $<$ or $=35$ years) having acute myocardial infarction: the detrimental role of continuation of smoking. Eur J Cardiovasc Prev Rehabil. 2008;15:567-71.

HJR.0b013e32830774db. PMID: 18769343.

16. Serban Puricelb, Cedric Lehnerb, Markus Oberhänslia,
Tobias Rutz, Mario Tognib, Mathieu Stadelmanna et al. Acute coronary syndrome in patients younger than 30 years -aetiologies, baseline characteristics and long-term clinical outcome. Swiss Med Wkly. 2013;143:13816.

17. Colkesen AY, Acil T, Demircan S, et al. Coronary lesion type, location, and characteristics of acute ST elevation myocardial infarction in young adults under 35 years of age. Coron Artery Dis. 2008;19:345-7. https:// doi.org/10.1097/MCA.0b013e3283030b3b.

PMID: 